\title{
Ecological Resilience Assessment of an Emerging Urban Agglomeration: A Case Study of Chengdu-Chongqing Economic Circle, China
}

\author{
Zhou Ying, Chen Yuan, Li Zhuolu, Jiang Weiling* \\ College of Architecture and Urban-Rural Planning, Sichuan Agricultural University, Dujiangyan 611830, China
}

Received: 19 July 2021

Accepted: 20 November 2021

\begin{abstract}
The rapid development of Chengdu-Chongqing Economic Circle (CCEC) has caused damage to the ecological environment. Exploring changes in the ecological resilience of Chengdu-Chongqing Economic Circle and improving post-disaster resilience will help improve the green, healthy and sustainable development of similar urban agglomerations in Chengdu-Chongqing Economic Circle. Considering 16 cities in Chengdu-Chongqing Economic Circle as examples, this paper uses the entropy and the linear weighting methods to calculate the ecological resilience level of Chengdu-Chongqing Economic Circle. Using the obstacle degree model, the paper studies the influence factors of ecological resilience level. Finally, Moran's I is used to study the spatial autocorrelation of the ecological resilience of Chengdu-Chongqing Economic Circle. The results show: (1) The overall ecological resilience level of Chengdu-Chongqing Economic Circle is showing an upward trend, but it is currently at an intermediate stage. (2) Disasters have a greater impact on the level of ecological resilience. (3) The spatial autocorrelation of CCEC has changed from negative correlation to positive correlation and then to negative correlation.
\end{abstract}

Keywords: Chengdu-Chongqing Economic Circle, ecological resilience, influencing factors, spatial autocorrelation

\section{Introduction}

China's rapid economic development is inseparable from urbanization. From 1999 to 2019, China's GDP increased by 10 times from $8,936.65$ billion

*e-mail: weiling.jiang@sicau.edu.cn
RMB to 9,8852.89 billion RMB. At the end of 2020, the urbanization rate of China's permanent population exceeds $60 \%$, and urbanization is full of uncertain damage to the quality of the ecological environment [1]. The process of economic development is also inseparable from industrialization. Urbanization and industrialization consume environmental resources, such as mineral resources, water resources and land resources. It results in an inevitable reduction 
of resources. China's total energy consumption rose from 141 to 487 million tons of standard coal from 1999 to 2019 . The process of industrialization inevitably produces waste, and the discharge of waste causes inevitable pollution to water, land and air. Climate change, water pollution, resource reduction, natural disasters and other phenomena frequently occur. Ecological environmental quality in China decreased significantly. Now, China has become the world's second-largest economy, and the disturbance of the ecosystem will affect the prospects of China's economic development and has become an obstacle to China's sustainable development.

As the United Nations proposed the 2030 Sustainable Development Goals in 2015, ecological environment assessment has become an increasingly popular research topic. As early as 1985, the European Commission put forward the Environmental Impact Assessment (EIA) Directive (85/337/EEC). Resources and ecological environment quality have become the focus of attention. The new EIA Directive (2014/52/EU) that took effect in 2014 directly mentioned biodiversity in the legislation for the first time [2]. With the resilience assessment framework proposed by the Rockefeller Foundation in the United States and the formulation of the "Risk Management and Resilience Improvement" plan in London, England, flexible urban development models have gradually attracted attention from all walks of life [3]. In 2020, the "Fourteenth Five-Year Plan for National Economic and Social Development of the People's Republic of China" proposes new progress in the construction of ecological civilization. Economic development and environmental protection are longstanding contradictions. In the process of economic and social development, if developing countries do not pay attention to adjusting the contradiction between development and the environment, environmental resources will become less and less.

According to "Chengdu-Chongqing Economic Construction Plan", the process of development should persist in ecological and environmental protection, take a new path of ecological priority and green development, and promote the harmonious coexistence of man and nature. As CCEC is an emerging urban agglomeration and located in southwestern China, its economic development is not as quick as that of Beijing-Tianjin-Hebei, Yangtze River Delta, Guangdong-Hong Kong-Macao Greater Bay Area and other urban agglomerations. Therefore, it needs to vigorously develop its economy. But in the process of economic development, the process of urbanization and industrialization will damage the ecosystem. Deterioration of water quality, climate change, land pollution, soil erosion and other phenomena have emerged one after another. The urbanization rate of CCEC is as high as $53.8 \%$ in 2019. However, the degraded grassland area in Sichuan accounted for $56.9 \%$ of the total usable grassland area, and the area of soil erosion in Chongqing accounted for $34.84 \%$ of the total land area. There are many types of climatic disasters, which occur frequently and cover a large area, mainly heavy rains and floods. In 2019, Sichuan Province and Chongqing City caused 36.05 billion $\mathrm{RMB}$ in direct losses due to disasters. And the quality of the ecological environment is significantly reduced. The high-quality development of CCEC is necessary [4]. The ecological environment is the basic framework that supports human survival and economic and social development.

Ecosystem footprint, ecosystem elements [5] and ecosystem services are the focus of researchers [6]. Ecological carrying capacity [7] and sensitivity [8, 9] are common research contents in ecosystems. Resilience originated in physics. Hoiling, as the first proponent, proposed that resilience refers to the ability of the system to quickly return to the original state or change to a new equilibrium state through self-adjustment, and maintain the normal operation of its structure and function [10]. After the concept of resilience was put forward, research on urban resilience continued to increase $[11,12]$. There are also studies applying the concept of resilience to other industries, such as the oil and gas industry [13]. Resilience evaluation methods include top-down and bottom-up evaluation methods. The bottom-up approach is usually qualitative. The top-down method is quantitative. Based on case study data, the resilience index of a specific analysis unit is calculated [14]. Ecological resilience refers to the ability of the ecosystem as a whole to restore to its original state and the ecosystem to recover from damage. In recent years, with the introduction of the concept of ecological resilience, research on the level of ecological resilience has continued to increase. Mainly divided into three parts:

As for studying ecological resilience from the perspective of the landscape, ecological resilience mainly adopts the theory of "source and sink". Based on the "source-sink" landscape theory, a framework of factors affecting the resilience of resource-based cities can be established. Carry out a quantitative analysis of restoration intensity [15] and propose the layout of ecological corridors based on the flexibility of ecological corridors [16] to achieve a more reasonable spatial layout [17] and improve ecological resilience. The disturbance source of ecological resilience can also be used to analyze the disturbance in the multidimensional disturbance space [18].

As for studying ecological resilience from the perspective of biological communities, biodiversity, functional redundancy and the spatial pattern will all affect ecological resilience [19]. The current quantitative research on ecological resilience mainly focuses on ecological network analysis (ENA) and cross-scale models. Both ENA and cross-scale models are powerful tools to measure ecological resilience [20]. In addition, the revised INVEST model can also study ecological resilience [21]. Seagrass system [22], plateau grassland system [23], bird community [24] and coral reef 
[25-27] are the main communities for ecological resilience research.

As for studying the resilience of the "socialecological" system, the "social-ecological" system more comprehensively assesses urban resilience [28]. $\mathrm{Hu}$ Mengmeng et al. studied the "social-ecological" composite system from the perspective of vulnerability and coping ability [29]. Multi-criteria analysis is the main spatial method [30]. With the development of landscape ecology and GIS, academia has gradually begun to study the "social-ecological" system from the spatial level [31]. The research on ecological resilience is based more on the resilience of the "socialecological" system. However, most scholars believe that ecological resilience is more suitable for urban research [32]. The research on ecological resilience has been carried out from different aspects, most of which are based on theoretical research, such as the research on the improvement of urban ecological resilience [33], the evolution of ecological resilience theory [34], and the ecological resilience of the evaluation index system [35]. The research theory of ecological resilience has begun to mature, but the relevant literature rarely mentions the evaluation of the level of ecological resilience of specific urban agglomerations. The research on ecological resilience lacks macro-quantitative analysis. The topdown method can quantify the inherent resilience, and the multi-criteria model has always been an important method of quantitative analysis [36-38]. Therefore, this paper will use a top-down method to quantify the level of ecological resilience in CCEC and study its influencing factors.

The main research purpose of this paper:

(1) Resilience is rarely mentioned in the relevant literature on ecological and environmental issues [39]. Especially the research on CCEC ecological resilience is relatively insufficient. The coupling system of man and nature is complicated in how to predict and respond to natural disasters. Therefore, this paper considers the impact of natural disasters when quantifying the level of CCEC's comprehensive ecological resilience. The DPSIR model is used to build an evaluation index system for ecological resilience from driving force, pressure, state, impact and response. The impact of disasters on the level of ecological resilience is explored in this paper.

(2) There are few studies on the ecological resilience of urban agglomerations, and there is a lack of spatial research. Therefore, this paper uses GIS (Geographic Information System) to study the temporal and spatial changes of CCEC's ecological resilience level. At the same time, Moran 'I is used to evaluate the spatial correlation of CCEC ecological resilience.

First, this paper calculates the ecological resilience level of CCEC and analyzes the spatial autocorrelation from 2009 to 2018. The impact of disasters on the ecological resilience level is taken into account when constructing the ecological resilience level index evaluation system. Then, the weight is used to calculate the factors that affect the level of ecological resilience. Finally, it provides policy recommendations that affect the green, healthy and sustainable development of CCEC.

\section{Material and Methods}

\section{Study Area}

As a new type of urban agglomeration in China, CCEC is an urbanized area with the highest level of development and the greatest development potential in western China. It is an important part of China's implementation of the Yangtze River Economic Belt and the "Belt and Road" construction. CCEC covers 16 cities including Chengdu, Dazhou, Zigong, Guang'an, Nanchong, Ya'an, Suining, Luzhou, Mianyang, Deyang, Ziyang, Neijiang, Meishan, Leshan, Yibin and Chongqing, covering Sichuan Province and Chongqing City. An urban agglomeration with a population of hundreds of millions, covering an area of 185,000 square kilometers, has two national-level central cities. CCEC is located in the Sichuan Basin with diverse climatic conditions. The overall air is humid, with heavy rainfall, and the annual rainfall can reach 1000-2000 mm. The rapid economic development of CCEC has a great impact on the ecological environment. In addition, the geological environment of CCEC is complex, therefore, the number of climate disasters is large, and the quality of the ecological environment is degraded. When the ecosystem is relatively fragile, its ecological elasticity level is low, and it is more strongly affected by human activities. Therefore, it is necessary to measure the level of CCEC's ecological resilience and study the influencing factors to improve ecological resistance and resilience. It is of great significance to promote China's sustainable development.

This paper collects panel data of 16 cities from 2009 to 2018, which come from the "China Statistical Yearbook", "Sichuan Province Statistical Yearbook", and "Statistical Yearbook" (2010-2019). Some data come from economic and social development statistical bulletins, ecological environment quality and water environment quality bulletins in 16 cities (2009-2018).

\section{Method of Constructing Ecological Resilience Evaluation System}

In this paper, the DPSIR model was used to construct an evaluation index system for the ecological resilience level. Driving Forces - Pressures - States - Impacts - Responses (DPSIR) framework is one of the original tools developed by the Organization for Economic Cooperation and Development (1993) and the European Environment Agency (EEA, 1995) to adapt to the environmental assessment system [40]. The EEA has adopted a conceptual framework (DPSIR) as the main 


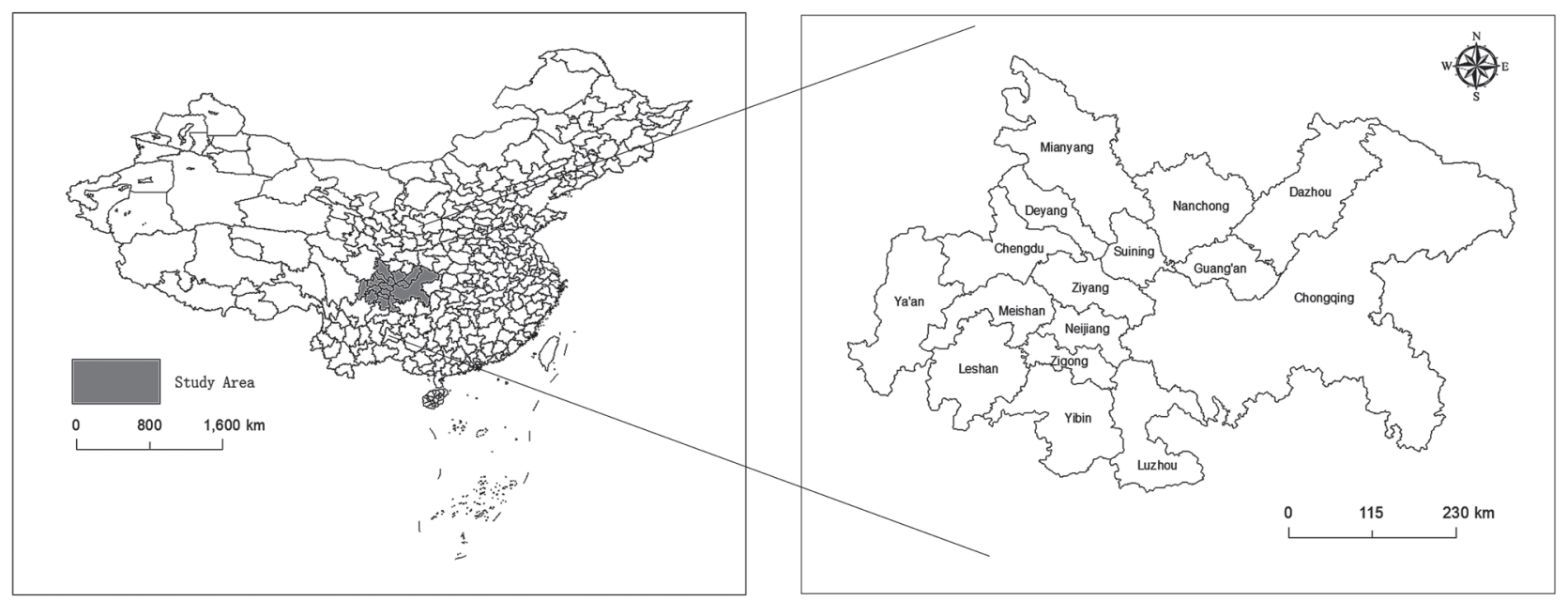

Fig. 1. The location of CCEC in China.

Table 1. Ecological resilience evaluation index system.

\begin{tabular}{|c|c|c|c|c|c|}
\hline Component & Unit & Indicator & Dimension & Impact & Weight \\
\hline \multirow{4}{*}{$\begin{array}{l}\text { Driving } \\
\text { forces }\end{array}$} & $\%$ & Urbanization rate $(\mathrm{D} 1)$ & Social & - & 0.039 \\
\hline & $\mathrm{P} / \mathrm{km}^{2}$ & The population density (D2) & Social & - & 0.041 \\
\hline & RMB & GDP per capita (D3) & Economic & - & 0.039 \\
\hline & RMB & Per capita consumption expenditure of urban residents (D4) & Economic & - & 0.038 \\
\hline \multirow{5}{*}{ Pressures } & $\mathrm{km}^{2}$ & Built-up area (P1) & Resource & - & 0.039 \\
\hline & $\mathrm{km}^{2}$ & Urban industrial construction land area (P2) & Resource & - & 0.038 \\
\hline & $\mathrm{L}$ & Per capita consumption of urban daily domestic water (P3) & Resource & - & 0.035 \\
\hline & $10^{4} \mathrm{t}$ & Industrial smoke (dust) emissions (P4) & Nature & - & 0.029 \\
\hline & $10^{4} \mathrm{t}$ & Industrial wastewater discharge (P5) & Nature & - & 0.033 \\
\hline \multirow{6}{*}{ States } & $\mathrm{mm}$ & Annual precipitation $(\mathrm{S} 1)$ & Nature & + & 0.039 \\
\hline & $\mathrm{km}^{2}$ & Green area $(\mathrm{S} 2)$ & Nature & + & 0.043 \\
\hline & $\%$ & Air quality compliance rate (S3) & Nature & + & 0.043 \\
\hline & $\%$ & Energy consumption per unit GDP index (S4) & Resource & - & 0.042 \\
\hline & $m^{3}$ & Per capita water resources (S5) & Resource & + & 0.050 \\
\hline & $10^{3} \mathrm{~h}$ & Actual cultivated land area at the end of the year (S6) & Resource & - & 0.068 \\
\hline \multirow{5}{*}{ Impacts } & ${ }^{\circ} \mathrm{C}$ & Average temperature (I1) & Climate & + & 0.045 \\
\hline & hours & Sunshine hours (I2) & Climate & + & 0.042 \\
\hline & $10^{8} \mathrm{RMB}$ & Loss due to disaster (I3) & Disaster & - & 0.052 \\
\hline & $10^{3} \mathrm{~h}$ & Damaged area of crops (I4) & Disaster & - & 0.038 \\
\hline & $10^{4} \mathrm{p}$ & Number of people affected (I5) & Disaster & - & 0.019 \\
\hline \multirow{5}{*}{ Responses } & - & Whether the emergency rescue plan is formulated (R1) & Disaster & + & 0.049 \\
\hline & $\%$ & Comprehensive utilization rate of general solid waste (R2) & Ecological & + & 0.030 \\
\hline & $\%$ & Urban sewage treatment rate (R3) & Ecological & + & 0.032 \\
\hline & $\%$ & Green coverage rate of built-up area (R4) & Ecological & + & 0.036 \\
\hline & $\%$ & Forest cover rate $(\mathrm{R} 5)$ & Ecological & + & 0.041 \\
\hline
\end{tabular}


method of ecological safety assessment [41]. It can more comprehensively reflect the compound relationship of "society-economy-environment-government".

The CCEC has rapid economic development and complex terrain. Therefore, in constructing the CCEC ecological resilience evaluation index system, based on the DPSIR model, the social, economic, environmental and governmental influences are considered. The specific index evaluation system is shown in Table 1 .

1. Driving forces refer to indicators that have no direct influence on the level of ecological resilience. This paper considers social and economic driving forces. It specifically considers the four driving forces of urbanization rate, the population density, GDP per capita and per capita consumption expenditure of urban residents.

2. Pressures refer to the factors that have a direct impact on the level of ecological resilience. This paper considers resource pressure and natural pressure. Specifically, it includes six pressure indicators: builtup area, urban industrial construction land area, per capita consumption of urban daily domestic water, industrial smoke (dust) emissions and industrial wastewater discharge.

3. States refer to the state of ecological resilience under driving forces and pressures. This paper considers the resource conditions and natural conditions. Specifically, six indicators include annual precipitation, green area, air quality compliance rate, energy consumption per unit GDP index, per capita water resources and actual cultivated land area at the end of the year.

4. Impacts mainly refer to the impact of ecological resilience under the influence of driving forces and pressures. The disaster impacts are especially considered when constructing the impact indicators. Therefore, based on the nature of the state and the availability of data, five indicators have been established: average temperature, sunshine hours, loss due to disaster, damaged area of crops, and number of people affected.

5. Responses refer to the policy and measure responses in the face of the impacts. Therefore, this paper considers the response to earthquake disaster mitigation and ecological environment protection. Specifically, it includes five indicators: whether the emergency rescue plan is formulated, the comprehensive utilization rate of general solid waste, urban sewage treatment rate, green coverage rate of built-up area and forest cover rate.

\section{Method for Calculating the Ecological Resilience of CCEC}

In this section, the entropy and linear weighting methods are used to calculate the ecological resilience level, and the natural breakpoint method is used to classify the ecological resilience level.

\section{Data Standardization}

In the multi-indicator evaluation system, the data is mostly in different dimensions and orders of magnitude. The Max-min standardization method is adopted in this paper. The specific formula is as follows:

When the indicator is a positive indicator:

$$
Y_{i j}=\frac{X_{i j}-\min \left\{X_{j}\right\}}{\max \left\{X_{j}\right\}-\min \left\{X_{j}\right\}}
$$

When the indicator is a negative indicator:

$$
Y_{i j}=\frac{\max \left\{X_{j}\right\}-X_{i j}}{\max \left\{X_{j}\right\}-\min \left\{X_{j}\right\}}
$$

Where, $X_{i j}$ refers to the data value corresponding to the $\mathrm{j}$ index in the i year, $\min \left\{X_{j}\right\}$ refers to the minimum value of the $\mathrm{j}$ index, and $\max \left\{X_{j}\right\}$ refers to the maximum value of the $\mathrm{j}$ index. The data values after data standardization are distributed between $[0,1]$.

\section{The Entropy Method}

For the structured data, the entropy method [42] is the most objective. This paper uses the entropy method to calculate the weight. The specific formula is as follows:

(1) Calculate the proportion of the data value of the $\mathrm{j}$ index in the $\mathrm{i}$ year, where $Y_{i j}$ is the standardized value of the $\mathrm{j}$ index in the $\mathrm{i}$ year, $P_{i j}^{i j}$ refers to the proportion of the data value of the $\mathrm{j}$ index in the $\mathrm{i}$ year. The formula is as follows:

$$
P_{i j}=\frac{Y_{i j}}{\sum Y_{i j}}
$$

(2) Calculate the entropy value of the $\mathrm{j}$ index, where $k=1 / \ln (\mathrm{n})$, satisfies $e_{j} \geq 0$. The formula is as follows:

$$
e_{i j}=-k \sum P_{i j} \ln \left(P_{i j}\right)
$$

(3) Calculate the difference coefficient of the $\mathrm{j}$ index. For the $\mathrm{j}$ index, the greater the difference of the index, the greater the influence on the scheme evaluation, and the smaller the entropy value. $d_{j}$ is the coefficient of difference. The formula is as follows:

$$
d_{j}=1-e_{j}
$$

(4) Calculate weights. The formula is as follows:

$$
w_{j}=\frac{d_{j}}{\sum d_{j}}
$$




\section{The Linear Weighting Method}

This paper uses the linear weighting method to evaluate the level of ecological resilience. The linear weighted summation of the objective function transforms the multi-objective problem into singleobjective programming [43].

The specific formula is as follows:

$$
S_{i}=\sum w_{j} * Y_{i j}
$$

\section{The Natural Breakpoint Method}

For the classification method of ecological resilience level, the natural breakpoint method is used for grading. The natural breakpoint method is a statistical method of grading and classifying according to numerical statistical distribution law, which can maximize the difference between classes. The classification of this paper is shown in Table 2.

\section{Method for Analyzing the Influencing Factors of Ecological Resilience Level}

Based on the evaluation system of ecological resilience level, this paper analyzes the impact of ecological resilience level by using the obstacle degree model [44]. The top six obstacle factors are selected. The formula is as follows:

$$
\begin{gathered}
U_{j}=w_{j} * w_{r} \\
J_{i j}=1-Y_{i j} \\
M_{i j}=\frac{U_{j} J_{i j}}{\sum U_{j} J_{i j}} * 100 \%
\end{gathered}
$$

Where, $w_{r}$ is the weight of $\mathrm{r}$ of the system layer to which index $\mathrm{j}$ belongs, which is obtained by summing the weight of each index; $U_{j}$ is the factor contribution degree of $\mathrm{j}$ index; $J_{i j}$ is the index deviation degree of the $\mathrm{j}$ index in the $\mathrm{i}$ year; $M_{i j}$ denotes the handicap degree of the $\mathrm{j}$ index in the $\mathrm{i}$ year.

Table 2. Ecological resilience classification.

\begin{tabular}{|c|c|c|}
\hline $\begin{array}{c}\text { Interval } \\
\text { levels }\end{array}$ & Interval ranges & $\begin{array}{c}\text { The level of ecological } \\
\text { resilience }\end{array}$ \\
\hline $\mathrm{A}$ & $0.000-0.540$ & High \\
\hline $\mathrm{B}$ & $0.540-0.558$ & Relatively high \\
\hline $\mathrm{C}$ & $0.558-0.616$ & Average \\
\hline $\mathrm{D}$ & $0.616-0.653$ & Relatively low \\
\hline $\mathrm{E}$ & $0.653-0.890$ & Low \\
\hline
\end{tabular}

\section{Method for Spatial Autocorrelation Analysis of Ecological Resilience Level}

The Moran's I is used to test the spatial autocorrelation of the ecological resilience level of CCEC. Use the global Moran's I to test the spatial difference of the ecological resilience level of CCEC. The specific local spatial correlation will be further visualized using Moran's scatter plot [45]. Moran's $\mathrm{I}>0$ indicates a positive spatial correlation, Moran's $\mathrm{I}<0$ indicates negative spatial correlation. Otherwise, Moran's $\mathrm{I}=0$ indicates spatial randomness. In this paper, the calculation of the Moran's I is calculated and the figure is drawn by Geoda software.

The formula is as follows:

$$
\begin{gathered}
\mathrm{I}=\frac{n}{S_{0}} \frac{\sum w_{i j} \sum z_{i} z_{j}}{\sum z_{i}^{2}} \\
S_{0}=\sum w_{i j}
\end{gathered}
$$

Where, $z_{i}$ is the deviation between the attribute of element I and its average value $\left(z_{i}-\bar{X}\right), w_{i j}$ is the spatial weight between element I and $j$; $\mathrm{n}$ is equal to the total number of elements and $S_{0}$ is the aggregation of all Spaces. The statistical score is calculated according to the following formula:

$$
Z_{I}=\frac{1-E[I]}{\sqrt{V[I]}}
$$

Among them:

$$
\begin{gathered}
E[I]=-\frac{1}{(n-1)} \\
V[I]=\mathrm{E}\left[I^{2}\right]-E[I]^{2}
\end{gathered}
$$

\section{Results and Discussion}

As Chongqing and Chengdu are national-level cities, they are the core cities of the CCEC. Chongqing is a municipality directly under the central government, and Chengdu, as a new first-tier city, ranked sixth in China's GDP in 2020. The economies and development scales of other cities are small, and even a few cities combined are not as good as Chengdu and Chongqing. Therefore, according to the general division of Sichuan, CCEC is divided into Western Sichuan, Southern Sichuan and Northern Sichuan according to geographical location. Chengdu originally belonged to Western Sichuan, but due to its large scale, Chengdu and Chongqing were separated into separate districts, as shown in Table 3. This paper explores the spatiotemporal variation and spatial autocorrelation analysis 
Table 3. Chengdu-Chongqing Economic Circle Division.

\begin{tabular}{|c|c|}
\hline Region & Contains city \\
\hline Chengdu & Chengdu \\
\hline Southern Sichuan & $\begin{array}{c}\text { Zigong, Luzhou, Neijiang, Yibin, } \\
\text { Ziyang, Deyang }\end{array}$ \\
\hline Western Sichuan & Leshan, Meishan, Ya'an \\
\hline Northern Sichuan & $\begin{array}{c}\text { Mianyang, Suining, Nanchong, } \\
\text { Guang'an, Dazhou }\end{array}$ \\
\hline Chongqing & Chongqing \\
\hline
\end{tabular}

of CCEC ecological resilience for the years 2009, 2012, 2015 and 2018.

\section{The Trend in the Level of Ecological Resilience in CCEC}

Formulas (1)-(2) are used to standardize the data and formulas (3)-(7) are used to calculate the ecological resilience level of CCEC. From 2009 to 2018, the level of ecological resilience in different regions is different, and the overall ecological resilience trend is shown in Fig. 2. It can be seen from Fig. 2 that the overall ecological resilience level of CCEC has risen at a slow speed. From 2012 to 2013, the ecological resilience of CCEC grew at a faster rate.

The change in the level of ecological resilience is a dynamic process. From 2009 to 2018, CCEC showed a rapid development trend. The regional GDP of Sichuan Province has increased by 1.87 times and that of Chongqing has increased by 2.1 times. In the process of urbanization and industrialization, resource consumption and environmental pollution have intensified, reducing the ecological resilience of CCEC. But when the economic and social development reaches the upper-middle level, people will begin to pay attention to the ecological environment. Take measures to reduce pollution and damage to the ecological environment, restore the ecological environment through policies and economics, and strengthen the construction of a disaster emergency system. Therefore, the overall ecological resilience of CCEC is showing an upward trend.

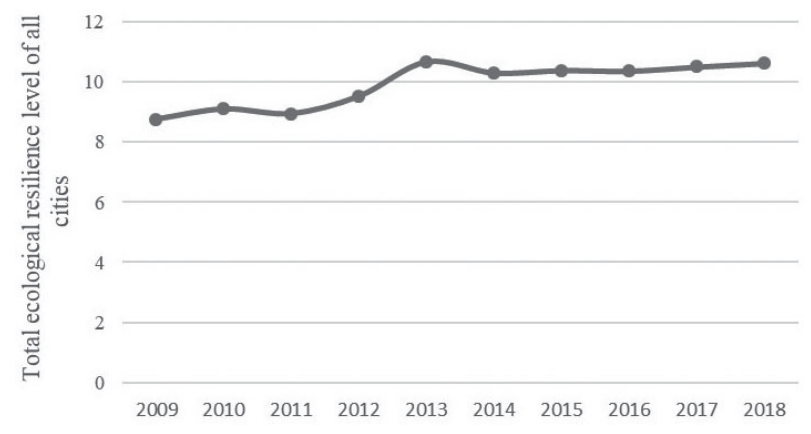

Fig. 2. Total ecological resilience level of all cities.
In 2012, the proportion of CCEC's secondary industry gradually declined, and the proportion of tertiary industry gradually increased, and the effects of industrial structure adjustment gradually appeared. That is, the process of industrialization is slow, and the damage to the ecology is reduced. However, the economy is still growing rapidly, and ecological and environmental protection has been intensified. Therefore, from 2012 to 2013, the ecological resilience of CCEC has grown rapidly.

Fig. 3 shows the detailed trends of the ecological resilience level of each city in CCEC. The ecological resilience levels of Chengdu, Zigong, Luzhou, Deyang, Leshan, Mianyang, Neijiang, Meishan, Yibin, Nanchong, Guang'an, Suining and Ziyang have shown an upward trend over time, while Ya'an has shown a downward trend. Moreover, Chongqing's ecological resilience level fluctuates greatly and declines rapidly from 2016 to 2018.

As shown in Fig. 3 the ecological resilience level of Chengdu, Zigong, Luzhou, Deyang, Leshan, Mianyang, Neijiang, Meishan, Yibin, Nanchong, Guang'an, Suining, and Ziyang has been on an upward trend from 2009 to 2013. The overall cities declined in 2014 or 2015. From 2016 to 2018, the level of ecological resilience gradually increased. Sichuan Province experienced rapid economic and social development in the four years from 2009 to 2013. The urbanization rate increased from $38.7 \%$ to $44.9 \%$, and the total GDP increased from $1,415.130$ billion RMB to $2,626.080$ billion RMB, an increase of $85.47 \%$. The development of urbanization and industrialization has increased the consumption of resources and the accumulation of waste discharge, causing damage to the ecological environment and exceeding the capacity of the ecological environment. Therefore, in 2014 and 2015, the ecological resilience has been greatly reduced, the overall temperature has risen, and the winter haze has been severe. From 2016 to 2018, production was restricted in industries such as industry, agriculture and construction, and the level of ecological resilience gradually increased.

Ya'an is located in a remote mountainous area, with steep terrain and many climatic disasters. In earthquake-prone areas, it is essential to make wise and strategic urban planning. Disaster risk reduction philosophy proactively promotes a "culture of disaster resilience" [46]. The Lushan earthquake damaged the ecological environment of Ya'an and reduced the ecological resilience of Ya'an in 2013. Moreover, the economic and social development of Ya'an is backward. To develop the economy and society, the quality of the ecological environment has been neglected, and the driving forces will increase the pressures. Therefore, the ecological environment resilience of Ya'an is in a state of decline.

The level of ecological resilience in Chongqing fluctuates greatly. As a "mountain city", Chongqing has more complicated geological and climatic conditions than other cities in CCEC. The frequency and intensity 


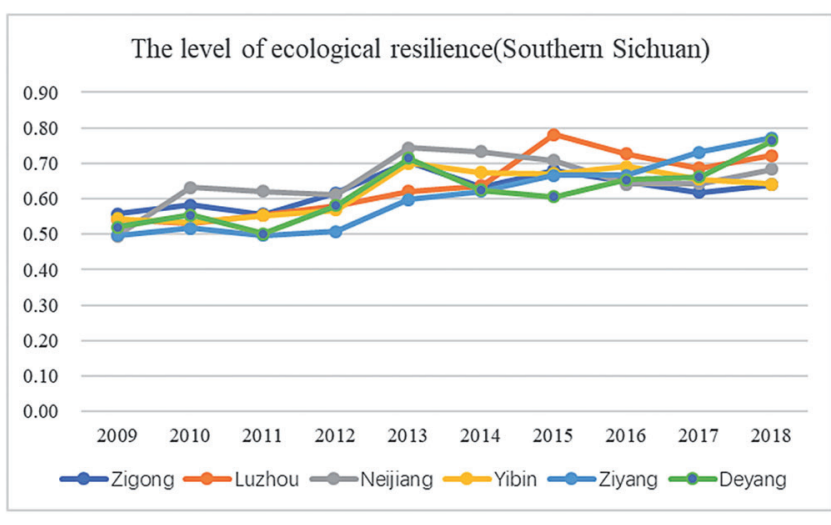

The level of ecological resilience(Northern Sichuan)

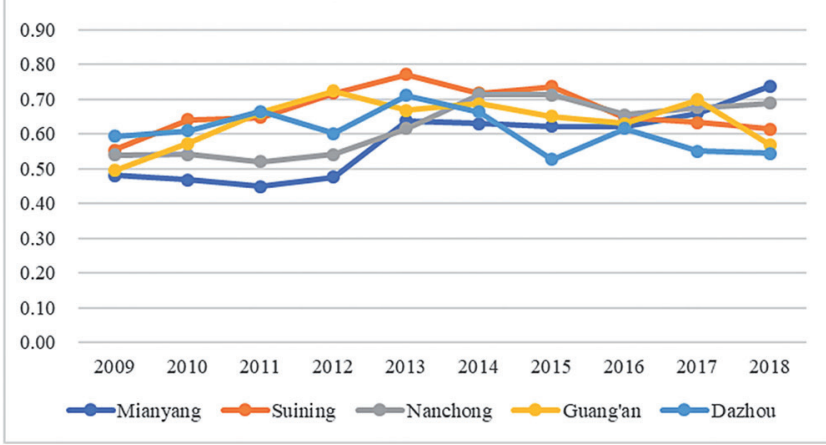

Fig. 3. The change of ecological resilience level.

of disasters are also higher. Moreover, Chongqing is a municipality directly under the Central Government. This makes its economic and social development more complicated than other cities. So its ecological resilience fluctuates more widely. From 2016 to 2018, the area and intensity of soil erosion in Chongqing continued to decline. Therefore, the ecological resilience of Chongqing declined rapidly between 2016 and 2018.

\section{Analysis of Factors Affecting the Ecological Resilience Level of CCEC}

According to the results calculated from the formulas (8)-(10) of the obstacle degree model, the obstacle degree results of each year are arranged in descending order, and the top six obstacle factors are taken as the dominant factors for each year. Taking the top six dominant factors with the highest frequency from 2009 to 2018 as the dominant factors in each city, the results in Table 4 are obtained. As table 4 is shown, per capita water resources, consumption per unit GDP index, loss due to disaster, forest cover rate, green coverage rate of built-up area and built-up area are the most frequent factors. Per capita water resources have the greatest impact on the ecological resilience level of CCEC, followed by the consumption per unit GDP index, followed by loss due to disaster. This shows that disasters have a greater impact on the ecological resilience of CCEC.

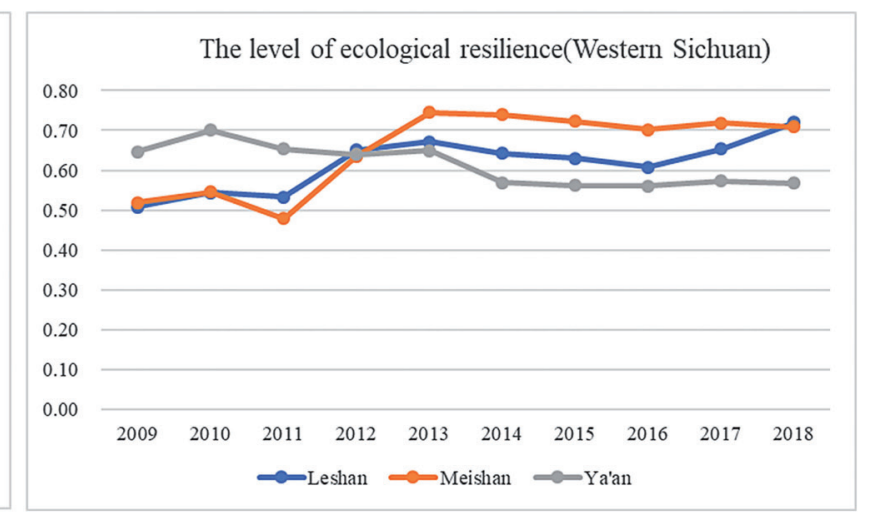

The level of ecological resilience(Chengdu \& Chongqing)

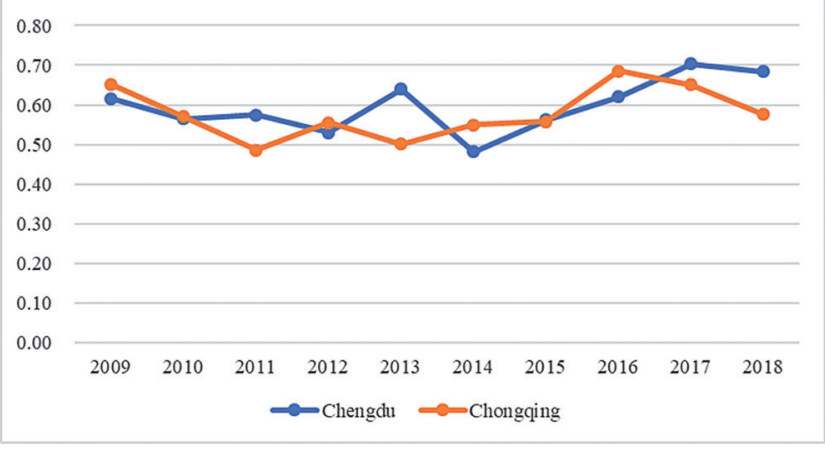

According to Table 2, the natural breakpoint method was used in ArcGIS to classify the ecological environment resilience levels in 2009, 2012, 2015, and 2018. The results are shown in Fig. 4.

As shown in Fig. 4, the level of ecological resilience in Northern Sichuan was relatively low, and it was relatively high in 2012, 2015, and 2018. The level of ecological resilience in Western Sichuan was relatively low in 2009 and relatively high between 2012 and 2018. The ecological resilience level in Southern Sichuan was low in 2009, average in 2012, high in 2015, and average in 2018. The level of ecological resilience in Chengdu was high in 2009, low in 2012, average in 2015, and high in 2018. The level of ecological resilience in Chongqing was high in 2009, low in 2012, and average in 2015 and 2018.

The ecological resilience level in Northern Sichuan rose in 2009 and remained at a stable relatively high from 2012 to 2018. The socio-economic development of the entire Northern Sichuan region is roughly the same as the national average, but the region is abundant natural resources. With economic and social development, although resources are consumed and the environment is polluted, resources are abundant. Moreover, the level of economic and social development is moderate, the public has a strong awareness of environmental protection, and the government's 
Table 4 .The result of Obstacle model.

\begin{tabular}{|c|c|c|c|c|c|c|}
\hline City $\quad$ Barrier factor & $\begin{array}{l}\text { First barrier } \\
\text { factor }\end{array}$ & $\begin{array}{l}\text { Second barrier } \\
\text { factor }\end{array}$ & $\begin{array}{l}\text { Third barrier } \\
\text { factor }\end{array}$ & $\begin{array}{l}\text { Fourth obstacle } \\
\text { factor }\end{array}$ & $\begin{array}{l}\text { Fifth barrier } \\
\text { factor }\end{array}$ & $\begin{array}{l}\text { Sixth barrier } \\
\text { factor }\end{array}$ \\
\hline Chengdu & $\mathrm{R} 4$ & S2 & I1 & $\mathrm{R} 5$ & S3 & S5 \\
\hline Zigong & $\mathrm{S} 4$ & $\mathrm{P} 2$ & P1 & S3 & S5 & S6 \\
\hline Luzhou & S4 & $\mathrm{R} 5$ & S5 & $\mathrm{R} 1$ & I3 & S2 \\
\hline Deyang & S5 & I2 & D4 & $\mathrm{I} 3$ & P5 & S4 \\
\hline Mianyang & P2 & S5 & $\mathrm{R} 4$ & S2 & S4 & S3 \\
\hline Suining & $\mathrm{R} 4$ & S5 & S4 & $\mathrm{I} 3$ & I4 & I1 \\
\hline Neijiang & S5 & S4 & P1 & $\mathrm{R} 5$ & I3 & D1 \\
\hline Leshan & $\mathrm{P} 2$ & S4 & S5 & $\mathrm{P} 1$ & $\mathrm{R} 4$ & R5 \\
\hline Nanchong & S5 & I1 & $\mathrm{R} 4$ & S3 & S4 & I3 \\
\hline Meishan & S4 & S5 & D4 & $\mathrm{R} 5$ & D3 & I3 \\
\hline Yibin & S5 & D2 & S3 & $\mathrm{I} 2$ & I3 & $\mathrm{R} 1$ \\
\hline Guang'an & S5 & $\mathrm{S} 1$ & S2 & $\mathrm{R} 4$ & S4 & I3 \\
\hline Dazhou & R3 & $\mathrm{S} 2$ & P2 & S1 & S5 & I1 \\
\hline Ya'an & $\mathrm{S} 4$ & P3 & $\mathrm{R} 2$ & $\mathrm{P} 1$ & R3 & S5 \\
\hline Ziyang & $\mathrm{P} 2$ & S5 & P1 & S4 & R5 & $\mathrm{I} 3$ \\
\hline Chongqing & $\mathrm{P} 2$ & S5 & S6 & $\mathrm{P} 1$ & S4 & $\mathrm{I} 3$ \\
\hline
\end{tabular}

ecological and environmental protection measures have been increasing. Therefore, the level of ecological resilience in Northern Sichuan has been increasing.

The ecological resilience level of Southern Sichuan rose steadily from 2009 to 2015 and declined in 2018. Due to the unique development of Sichuan, Chengdu is far ahead in the development of the capital city of Sichuan. In 2018, Chengdu's GDP was more than 6 times that of Mianyang, the second-ranked city. This shows that it is difficult to develop a city alone to reach or approach the level of Chengdu. Therefore, the fast-growing southern Sichuan region has become a key economic complex for the development of Sichuan Province. In 2014, the "South Sichuan Economic Zone Cooperation and Development Agreement" was formally signed, marking the beginning of the rapid development of the southern Sichuan urban agglomeration. Southern Sichuan is a city with scarce resources. Due to rapid economic and social development, the resources stress on environmental conditions and impact is greater than the response to ecological environmental protection. Therefore, in just three years, the level of ecological environmental resilience dropped to an average level.

Western Sichuan has been on the rise from 2009 to 2018. Western Sichuan is vast and sparse, and the terrain is complex. Due to the slow economic and social development, the pressure on resource consumption in Western Sichuan is relatively small. Moreover, each city in Western Sichuan has its own unique economic development body, mostly in the tourism industry, and the process of industrialization is slow. Tourism has promoted the economy and society of Western Sichuan, but it has caused relatively little pressure on the ecological environment. In addition, the economy and society have been developing, so the awareness of responding to ecological environment protection is increasing. Therefore, the ecological environment resilience level in Western Sichuan has been increasing and has even reached a high level.

The ecological resilience level of Chengdu fluctuated largely. Chengdu is the capital city of Sichuan Province, with rapid economic and social development, and the process of urbanization and industrialization is inevitable. The economic and social driving forces are far greater than in other cities. The problems of building construction, automobile exhaust and construction site dust caused by urbanization have increased the pressures on resources and the environment. In addition, economic and social development has reached a level that arouses awareness of ecological protection, and the responses to ecological environmental protection policies are increasing. When driving forces, pressures, impacts, states, and responses are all increasing, the influence of each factor is also changing frequently. Therefore, the ecological resilience level fluctuates greatly.

The ecological resilience level of Chongqing fluctuated greatly from 2009 to 2012 and stabilized from 2015 to 2018 . Chongqing is a municipality directly under the Central Government, known as a mountain city, and its economic and social development is faster than in other cities. The geological conditions 


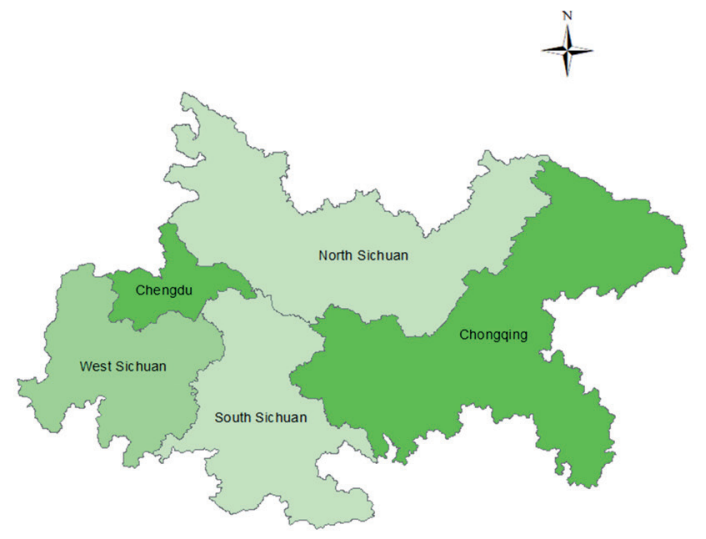

The level of ecological resilience
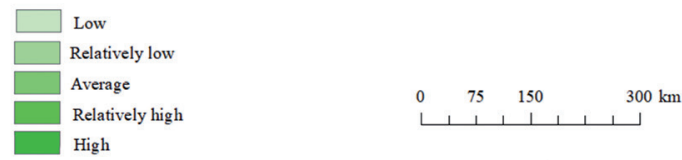

(a)2009

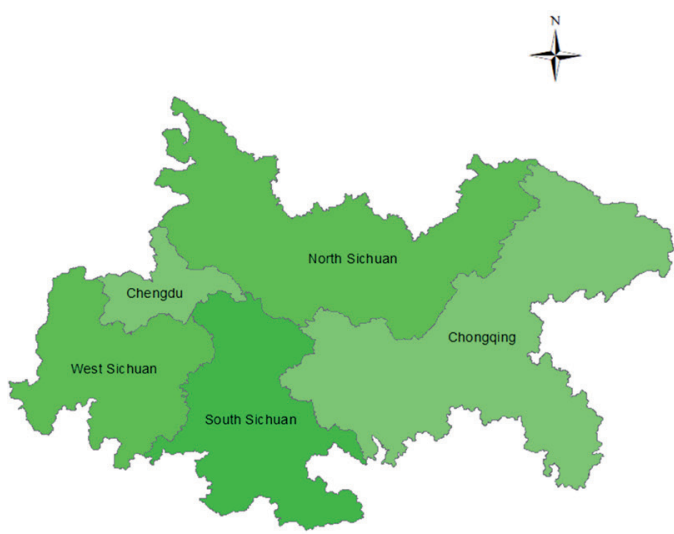

The level of ecological resilience
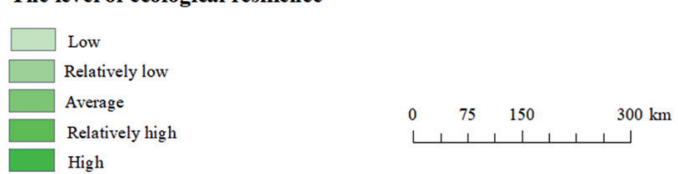

(c) 2015

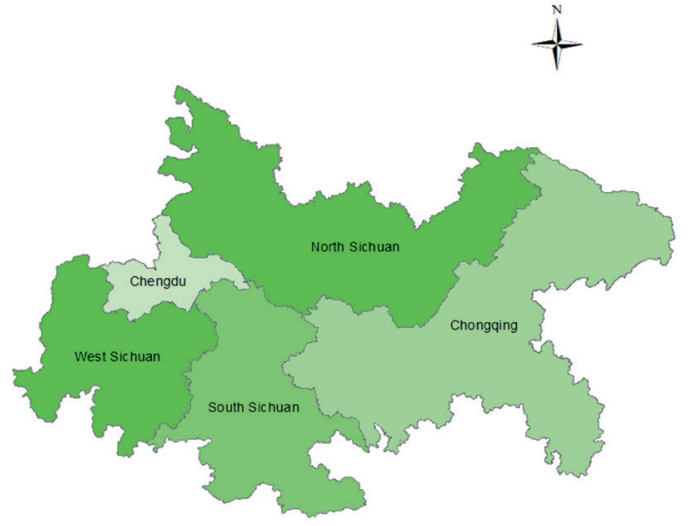

The level of ecological resilience
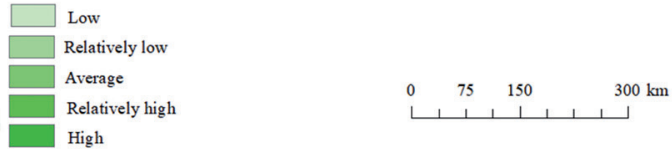

(b)2012

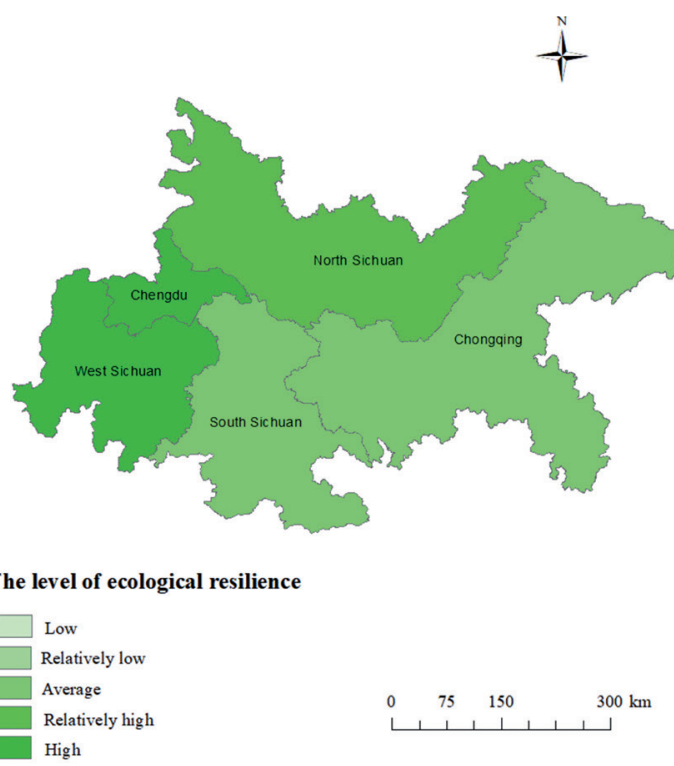

(d) 2018

Fig. 4. The result of ecological resilience classification.

of Chongqing are very complicated, the frequency of disasters is high, and the resources consumed for urban construction are also relatively large, so it dropped significantly from 2009 to 2012. The vulnerability of the ecological subsystem increases first and then decreases in Chongqing [47]. But in the same way, the responses to ecological and environmental protection policies will be faster. Therefore, the resilience of Chongqing's ecological environment has stabilized after 2015. Regions with few emergency shelters have low levels of resilience [48], so CCEC infrastructure needs to be strengthened.

\section{Spatial Autocorrelation Analysis of Ecological Resilience in CCEC}

In this paper, Moran's I is used to calculate the spatial autocorrelation of the ecological resilience level of CCEC by formula (11)-(15). In addition, the Moran's I is calculated for CCEC, and the value-p tests are performed. The result is shown in Table 5. In 2009, 2012 and 2018, CCEC showed a strong negative correlation, that is, the more geographically dispersed, the higher the level of ecological resilience. However, in 2015, the ecological resilience level of CCEC showed a positive correlation, that is, the more concentrated the geographical location, the higher the ecological resilience level. 
Table 5. The result of Moran's I.

\begin{tabular}{|c|c|c|}
\hline Years & Moran's I & Value-p \\
\hline 2009 & -0.076 & 0.421 \\
\hline 2012 & -0.144 & 0.003 \\
\hline 2015 & 0.028 & 0.050 \\
\hline 2018 & -0.013 & 0.089 \\
\hline
\end{tabular}

In 2015, the CCEC spatial correlation changed from negative correlation to positive correlation. The level of CCEC's ecological resilience has changed from spatial dispersion to spatial agglomeration. In 2015, the economic and social development of CCEC was much greater than in 2009. In a period of slow economic and social development, the more scattered the area, the more green areas and resources, and the higher the ecological resilience. With the rapid economic and social development, the more concentrated the policy protects between different regions, the higher the ecological resilience is. But in 2018, the CCEC spatial correlation changed from positive correlation to negative correlation. Due to the rapid economic and social development in 2018, the differences in social and economic development in various regions have become larger, resulting in uneven resource allocation and large differences in policy implementation. Therefore, in 2018, it has become spatially dispersed. After the Middle Reaches of the Yangtze River is affected by COVID-19, the spatial correlation is spatial clustering [49], while the spatial correlation of CCEC is still spatially discrete in 2018. It shows that CCEC also needs to strengthen the coordinated and common development of various regions to achieve the integrated development of CCEC.

This paper uses local Moran's I to test the spatial agglomeration of CCEC's ecological resilience. The LISA cluster map represents the spatial agglomeration of different regions, as shown in Fig. 5. In 2009, Ya'an showed the characteristics of high ecological resilience level and low surrounding areas, which was not significant in the other 15 cities. In 2012, 16 cities were not significant. In 2015, Mianyang and Ya'an showed their characteristics of low surroundings, Nanchong, Suining, Guang'an, Suining, Ziyang, Zigong and Yibin showed their characteristics of high surroundings and high surroundings, while the other 8 cities were not significant. In 2018, Ya'an presented its characteristics of low surrounding areas, which are not significant in other cities.

In 2009, Ya'an had relatively high ecological resilience, while the surrounding areas had relatively low ecological resilience. Ya'an City covers a large area
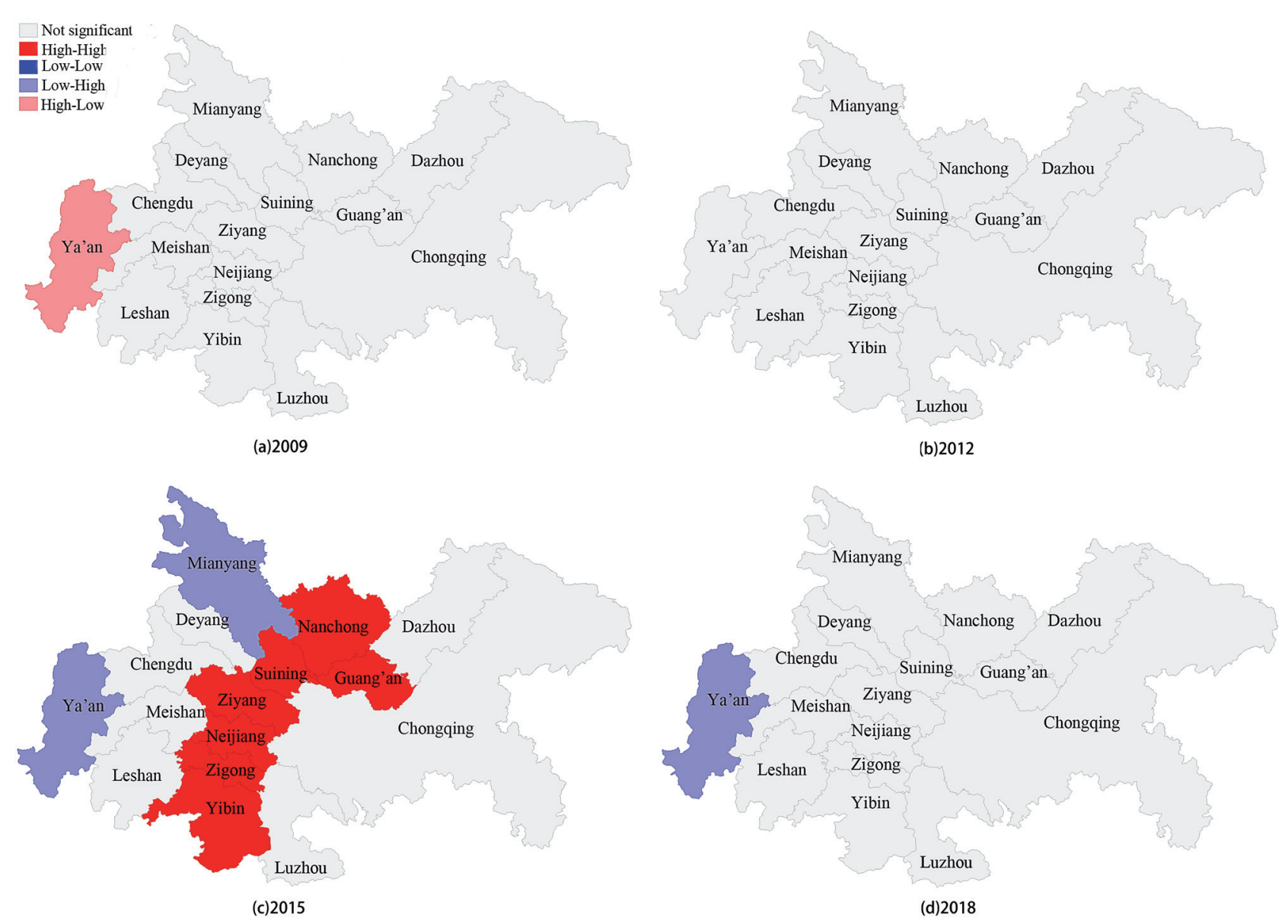

Fig. 5. LISA cluster map. 
and has a small population. Its social and economic development is slow and the degree of development is low. In 2009, when economic and social development was slow, the pressure on ecological resilience was small, so Ya'an City showed a high-low spatial aggregation.

In 2012, CCEC spatial agglomeration was not significant. In 2012, CCEC was in a state of social and economic development. The areas with faster economic and social development in Chengdu and Chongqing have correspondingly greater pressure on ecological resilience. However, other cities have developed slowly and the pressure on ecological resilience is relatively small. The ecological resilience level of each city is roughly the same. Therefore, CCEC appears insignificant.

In 2015, Mianyang and Ya'an showed their low-high characteristics, while Nanchong, Suining, Guang'an, Suining, Ziyang, Zigong, and Yibin showed their high- high characteristics. The other 8 cities were not significant. In 2013, a major earthquake occurred in Ya'an City, which greatly reduced the level of ecological resilience. Mianyang is an economic development body second only to Chengdu in Sichuan Province, with strong economic and social development, but the response measures have not kept up. Therefore, the ecological resilience is lower than that of the surrounding cities. Nanchong, Suining, Guang'an, Suining, Ziyang, Zigong and Yibin are abundant natural resources and the climate is relatively stable. There are more rural areas, relatively low industrial development and urbanization, and less damage to the ecological environment, which makes the level of ecological resilience in them higher than that in the surrounding areas.

In 2018, Ya'an presents its characteristics of lowhigh. Ya'an City is located in the transition zone from the Sichuan Basin to the Qinghai-Tibet Plateau, with high frequency of disasters. There are more than 1,300 hidden geological disasters in the city alone. Disasters have a greater impact on the level of ecological resilience. Moreover, landscape diversity is one of the important factors affecting the comprehensive resilience of a city [50]. Ya'an has complex geological conditions, and its landscape diversity is low compared to other cities. Therefore, Ya'an showed a low-high spatial clustering in 2018.

The ecological fragility of Chengdu-Chongqing area is relatively high in China's urban agglomerations, with the highest proportion of severely ecologically fragile areas [51]. Therefore, measuring the resilience of the Chengdu-Chongqing area is very important for the sustainable development of CCEC. In previous studies. The resilience level of the whole of China, including the Guanzhong Plain urban agglomeration and the $\mathrm{Su}-\mathrm{Xi}$-Chang urban agglomeration, is on the rise [52, 53]. This is consistent with our research results. The ecological resilience of CCEC is also on an upward trend. Gansu Province presents the spatial distribution characteristics of high ecological resilience around the economic development center [54], which is contrary to the findings of CCEC. Because the overall development level of CCEC is higher than that of Gansu, the over-development of the economic development center has caused too much damage to the ecological environment. Therefore, the ecological resilience level of surrounding cities is higher than that of Chengdu and Chongqing.

\section{Conclusions}

\section{Conclusions from the Analysis}

The ecological resilience system of CCEC is complex and fragile. Considering both time and space scales is crucial to understanding the resilience of the system [55]. The ecological resilience system includes social, economic, and ecological aspects. It can selfregulate within a certain degree of damage. Taking into account the conditions and characteristics of CCEC, a disaster-related ecological resilience evaluation index system has been established. The entropy and linear weighting method are used to calculate the ecological resilience level. The obstacle degree model is used to analyze the influencing factors of the ecological resilience level in CCEC. Finally, Moran's I is used to analyze the spatial autocorrelation of CCEC.

Therefore, this paper draws the following conclusions. Firstly, the ecological resilience level of CCEC is in a dynamic state, and the overall ecological resilience level of CCEC is showing an upward trend. Secondly, disasters have a great impact on the level of ecological resilience. Finally, the spatial autocorrelation of CCEC has changed from negative correlation to positive correlation and then to negative correlation. The conclusions drawn in this paper apply to emerging urban agglomerations similar to CCEC, such as $\mathrm{Su}-$ $\mathrm{Xi}$-Chang urban agglomeration. As an emerging urban agglomeration, the economy and society are developing rapidly, and the level of ecological resilience is constantly improving. In the development process, the economy, society, and ecology need to develop in a coordinated manner. When studying the ecological resilience of urban agglomerations, the DPSIR model used in this paper to construct the evaluation index system and Moran's I used in spatial autocorrelation analysis are also applicable.

However, this study has shortcomings. Firstly, when the data sample is relatively small, the results obtained by Moran's I in the spatial autocorrelation analysis are not significant compared to when the sample is large. At this time, the spatial weight matrix between regions needs to be manually defined. Secondly, as part of disaster data is not available, when constructing the evaluation index system, the consideration of disaster indicators is not comprehensive. In addition, more accurate computer languages are used for research. 


\section{Policy Recommendations}

The overall ecological resilience of CCEC is slowly improving. CCEC is an emerging urban agglomeration, and the huge economic and social driving force has increased the pressure on the environment and resources. Therefore, this paper recommends that CCEC take the path of sustainable development and green and healthy development, improve the level of ecological resilience, and form a healthy and resilient urban agglomeration.

(1) The ecological resilience of CCEC is slowly improving, but they are all in the upper-middle stage. Due to the large differences in social and economic development in various regions, strategies for improving ecological resilience should be different. For Chengdu and Chongqing, their GDP ranks among the top ten in China, with rapid economic development and low ecological environment quality. The coordinated development of economy and environment should be strengthened. For areas with slower economic development in areas such as Northern Sichuan, Southern Sichuan, and Western Sichuan, it is necessary to use resources to promote economic and social development, realize the complementary advantages of natural resources, tourism and other resources, and focus on diversified development to promote economic and social development.

(2) Disasters have a greater impact on the ecological resilience of CCEC. For cities with more disasters, such as Ya'an and Chongqing, more attention should be paid to earthquake prevention and disaster reduction measures. The government should improve infrastructure and rationally allocate public resources. At the same time, measures for disaster prevention and early warning and post-disaster recovery should be strengthened.

(3) As the spatial autocorrelation of CCEC changes from negative correlation to positive correlation and then to negative correlation. CCEC should strengthen regional coordinated development. For example, a cross-city coordination organization can be established to actively integrate into CCEC. At the same time, highlow agglomeration areas and low-high agglomeration areas should strengthen regional cooperation.

\section{Acknowledgments}

This paper was supported by Sichuan Agricultural University, the Tuojiang Basin High Quality Development Research Center (TJGZL2019-14), Sichuan Circular Economy Research Center (XHJJ1906), Economic Information and Technology Bureau of Yucheng District, Ya'an, China Panxi Health Care Industry Research Center (PXKY-YB-202006), the Chengdu/Sichuan New Pattern of Dual-Circular Development Research Center (CDNUSXH2021YB-01), Sichuan County Economic Development Research
Center (xy2021008), and Sichuan Provincial Key Research Base of Social Sciences (xy2021008).

\section{Conflict of Interest}

The authors declare no conflict of interest.

\section{References}

1. ERNSTSON H., VAN DER LEEUW S.E., REDMAN C.L., REDMAN C.L., MEFFERT D.J., DAVIS G., ALFSEN C., ELMQVIST T. Urban Transitions: On Urban Resilience and Human-Dominated Ecosystems. J. AMBIO. 39 (8), 531, 2010.

2. DRAYSON K., WOOD G., THOMPSON S. An evaluation of ecological impact assessment procedural effectiveness over time. J. Environmental Science \& Policy. 70, 54, 2017.

3. ZAIDI R Z., PELLING M. Institutionally configured risk: assessing urban resilience and disaster risk reduction to heat wave risk in London. J. Urban Studies, 52 (7), 1218, 2015

4. TU J., KUANG R., MAO K., NANXI L. Evaluation on High-Quality Development of Chengdu-Chongqing Urban Agglomeration. J. Economic Geography. 43, 1126, 2020 [In Chinese].

5. LIU W., ZHAN J., ZHAO F., WEI X., ZHANG F. Exploring the coupling relationship between urbanization and energy eco-efficiency: A case study of 281 prefecturelevel cities in China. J. Sustainable Cities and Society. 64, 102563, 2021.

6. CARO C., MARQUES J.C., CUNHA P.P., ZARA T. Ecosystem services as a resilience descriptor in habitat risk assessment using the InVEST model. J. Ecological Indicators. 115, 106426, 2020.

7. LEEUWA J.D., AFAG R.G, ELMADDIN N, EMIL B, MICHAEL T. MARSHALL M T, ETZOLD J, NEUDERT R. Application of the MODIS MOD 17 Net Primary Production product in grassland carrying capacity assessment. Int J Appl Earth Obs Geoinformation. 78, 66, 2019.

8. YANGFAN L., YALOU S., SALMAN Q., ANTJE B., XIAODONG Z. Applying the concept of spatial resilience to socio-ecological systems in the urban wetland interface. J. Ecological Indicators. 42, 135, 2014.

9. ROSSI P., PECCI A., AMADIO V., ROSSI O., SOLIANI L. Coupling indicators of ecological value and ecological sensitivity with indicators of demographic pressure in the demarcation of new areas to be protected: The case of the Oltrepò Pavese and the Ligurian-Emilian Apennine area (Italy). J. Landscape and Urban Planning. 85 (1), 12, 2008.

10. HOILING C.S. Resilience and stability of ecological systems. Annual Review of Ecology and Systematics, 4, $1,1973$.

11. 1RIBEIRO P.J.G, PENA JARDIM GONÇALVES L.A. Urban resilience: A conceptual framework. J. Sustainable Cities and Society. 50, 101625, 2019.

12. SCHLÖR H., SANDRA V.J.H. The FEW-Nexus city index - Measuring urban resilience. J. Applied Energy. 02, 026, 2017.

13. BENTO F., GAROTTI L., MERCADO M.P. Organizational resilience in the oil and gas industry: A scoping review. Safety science. 133, 105036, 2021. 
14. CARIOLET J., VUILLET M., DIAB Y. Mapping urban resilience to disasters - A review. J. Sustainable Cities and Society. 51, 101746, 2019.

15. WANG S.C., YUN Y.X., JIA Q. Ecological Resilience Evaluation of Central Urban Area of Tianjin Based on "Source-Flow-Sink" Index Analysis. Journal of Human Settlements in West China. 35 (1), 82, 2020 [In Chinese].

16. WU X., ZHANG J., GENG X., WANG T., WANG K., LIU S. Increasing green infrastructure-based ecological resilience in urban systems: A perspective from locating ecological and disturbance sources in a resource-based city. J. Sustainable Cities and Society. 61, 102354, 2020.

17. JIANG M., CHEN H., CHEN Q. A method to analyze "source-sink" structure of non-point source pollution based on remote sensing technology. J. Environmental Pollution. 182, 135-140, 2013.

18. GLADSTONE-GALLAGHER R.V., PILDITCH C.A., STEPHENSON F., THRUSH S.F. Linking Traits across Ecological Scales Determines Functional Resilience. J. Trends in Ecology \& Evolution. 34 (12), 1080, 2019.

19. ADGER W.N. Social-Ecological Resilience to Coastal Disasters. J. Science. 309 (5737), 1036, 2005.

20. NATHWANI J., LU X., WU C., FU G., XIAONAN Q. Quantifying security and resilience of Chinese coastal urban ecosystems. J. Science of The Total Environment. 672, 51, 2019.

21. SUNDSTROM S.M., ANGELER D.G., BARICHIEVY C., EASON T., GARMESTANI A., GUNDERSON L., KNUTSON M., NASH K.L., SPANBAUER T., STOW C., ALLEN C.R. The distribution and role of functional abundance in cross-scale resilience. DR. SHANA M. SUNDSTROM, 03, 2018.

22. ZHANG Y., LI C., ZHAO J., LI W., ZHANG P. Seagrass resilience: Where and how to collect donor plants for the ecological restoration of eelgrass Zostera marina in Rongcheng Bay, Shandong Peninsula, China. J. Ecological Engineering. 158, 106029, 2020.

23. GANJURJAV H., ZHANG Y., GORNISH E.S., GUOZHENG H., YUE L., YUNFAN W., QINGZHU G. Differential resistance and resilience of functional groups to livestock grazing maintain ecosystem stability in an alpine steppe on the Qinghai-Tibetan Plateau. Journal of Environmental Management. 251, 109579, 2019.

24. ROBERTS C.P., TWIDWELL D., ANGELER D.G., ALLEN C.R. How do ecological resilience metrics relate to community stability and collapse? J. Ecological Indicators. 107, 105552, 2019.

25. BELLWOOD D.R., HUGHES T.P., FOLKE C., NYSTRO"M M. Confronting the coral reef crisis. J. Nature. 429 (6994), 827, 2004.

26. MCLEOD E., SHAVER E.C., BEGER M., KOSS J., GRIMSDITCH G. Using resilience assessments to inform the management and conservation of coral reef ecosystems. J. Journal of Environmental Management. 277, 111384, 2021.

27. JOSHUA E., CINNER., MICHELE L. BARNES. Social Dimensions of Resilience in Social-Ecological Systems. One Earth Primer, 08, 003, 2019.

28. FOLKE C. Resilience: The emergence of a perspective for social-ecological systems analyses. J. Global Environmental Change. 16 (3), 253, 2006.

29. HU M., ZHANG J., HUANG J. Assessing SocialEcological System Resilience in Mainland China. Polish Journal of Environmental Studies. 27 (3), 1085, 2018.

30. NOBLE M.M., HARASTI D., PITTOCK J., DORAN B. Linking the social to the ecological using GIS methods in marine spatial planning and management to support resilience: A review. J. Marine Policy. 108, 103657, 2019.

31. ZHANG H., LIANG X., CHEN H. SHI Q. Spatio-temporal evolution of the social-ecological landscape resilience and management zoning in the loess hill and gully region of China. J. Environmental Development. 100616, 2021.

32. XIAO W., LV X., ZHAO Y., SUN H., LI J. Ecological resilience assessment of an arid coal mining area using index of entropy and linear weighted analysis: A case study of Shendong Coalfield, China. J. Ecological Indicators. 109, 105843, 2020.

33. COLDING J. 'Ecological land-use complementation' for building resilience in urban ecosystems. Landscape and Urban Planning. 81, 46, 2006.

34. BENNETT E.M., CUMMING G.S., PETERSON G.D. A Systems Model Approach to Determining Resilience Surrogates for Case Studies. J. Ecosystems. 8 (8), 945, 2005.

35. CABELL J.F., OELOFSE M. An Indicator Framework for Assessing Agroecosystem Resilience. J. Ecology and society. 17 (1), 18, 2012.

36. ZHANG Y., YANG Y., CHEN Z., ZHANG S. Multicriteria assessment of the resilience of ecological function areas in China with a focus on ecological restoration. J. Ecological indicators. 119, 106862, 2020.

37. WU X., HU F. Analysis of ecological carrying capacity using a fuzzy comprehensive evaluation method. J. Ecological indicators. 113, 106243, 2020.

38. DIDIER L BAHO., CRAIG R. ALLEN., AHJOND GARMESTANI 3., HANNAH FRIED-PETERSEN., SOPHIA E. RENES., LANCE GUNDERSON., DAVID G., Angeler A quantitative framework for assessing ecological resilience. J. Ecology and Society. 22 (3),17, 2017.

39. SOURCE L.G. Ecological and Human Community Resilience in Response to Natural Disasters. Z. Ecology and Society, 15 (2), 18, 2010.

40. GARI S.R., NEWTON A., ICELY J.D. A review of the application and evolution of the DPSIR framework with an emphasis on coastal social-ecological systems. J. Ocean \& Coastal Management. 103, 63, 2015.

41. HAN G., SHI Y., LU Y., LIU C., CUI, H., ZHANG, M. Coupling relation between urbanization and ecological risk of PAHs on coastal terrestrial ecosystem around the Bohai and Yellow Sea. J. Environmental Pollution. 268, 115680, 2021.

42. WANG Z., LIANG L., SUN Z., WANG, X. Spatiotemporal differentiation and the factors influencing urbanization and ecological environment synergistic effects within the Beijing-Tianjin-Hebei urban agglomeration. J. Journal of Environmental Management. 243, 227, 2019.

43. HU Y., MA J., LI XUEYA. Ecological Security Evaluation and Diagnosis of Obstacle Factors in the Beijing-TianjinHebei Region. J. Environmental Pollution and Control. 43 (02), 206, 2021 [In Chinese].

44. LIU H., HUANG B., YANG C. Assessing the coordination between economic growth and urban climate change in China from 2000 to 2015. J. Science of The Total Environment. 732, 139283, 2020.

45. MA F., WANG Z., SUN Q., YUEN., KUM F., ZHANG, Y., XUE H., ZHAO S. Spatial-Temporal Evolution of Urban Resilience and Its Influencing Factors: Evidence from the Guanzhong Plain Urban Agglomeration. J. Sustainability. 12 (7), 2593, 2020.

46. RANA I.A. Disaster and climate change resilience: A bibliometric analysis. J. International journal of disaster risk reduction. 50, 101839, 2020. 
47. LIU C., HE Q., LI Y. Spatiotemporal Evaluation of SocioEcological-Economic System Vulnerability: A CountyLevel Analysis of Chongqing, China. J. Sustainability. 12 (9), 3912, 2020.

48. ZHANG X., SONG J., PENG J., WU J. Landslides-oriented urban disaster resilience assessment - A case study in ShenZhen, China. J. Science of The Total Environment. 661, 95, 2019.

49. HOU X., MA Q., WANG X. Spatial Differentiation and Elements Influencing Urban Resilience in the Middle Reaches of the Yangtze River under the COVID-19 Pandemic. J. Discrete Dynamics in Nature and Society. 2021, 1, 2021.

50. FENG X., LEI J., XIU C., BAI J., LIMIN Z., XI Y. Analysis of Spatial Scale Effect on Urban Resilience: A Case Study of Shenyang, China. J. Chinese Geographical Science. 30 (6), 1005, 2020.

51. ZOU H., DUAN X., YE L., WANG L. Locating Sustainability Issues: Identification of Ecological Vulnerability in Mainland China's Mega-Regions. J. Sustainability. 9 (7), 1179, 2017.
52. ZHAO R., FANG C., LIU H., LIU, X. Evaluating urban ecosystem resilience using the DPSIR framework and the ENA model: A case study of 35 cities in China. J. Sustainable Cities and Society. 72, 102997, 2021.

53. ZHANG C., LI Y., ZHU X. A Social-Ecological Resilience Assessment and Governance Guide for Urbanization Processes in East China. J. Sustainability. 8 (11), 1101, 2016.

54. YANG X., ZHANG D., LIU L., NIU J., ZHANG X., WANG, X. Development trajectory for the temporal and spatial evolution of the resilience of regional tourism environmental systems in 14 cities of Gansu Province, China. J. Environmental Science and Pollution Research. 2021.

55. STOKOLS D., LEJANO R.P., HIPP J. Enhancing the Resilience of Human-Environment Systems: a Social Ecological Perspective. J. Ecology and Society. 18 (1), 7, 2013. 
